\title{
EDITORIAL
}

\section{Why we should use long-acting injectable antipsychotics more frequently}

João Paulo Maia-de-Oliveira, ${ }^{1,2,3}$ Rodrigo A. Bressan, ${ }^{4}$ Helio Elkis, ${ }^{5}$ João Paulo Machado-de-Sousa, ${ }^{1,2}$ Jaime E.C. Hallak ${ }^{1,2}$

${ }^{1}$ Department of Neuroscience and Behavior, Faculdade de Medicina de Ribeirão Preto, Universidade de São Paulo (USP), Ribeirão Preto, SP, Brazil. ${ }^{2}$ National Science and Technology Institute for Translational Medicine (INCT-TM), Conselho Nacional de Desenvolvimento Científico e Tecnológico (CNPq). ${ }^{3}$ Department of Clinical Medicine, Universidade Federal do Rio Grande do Norte (UFRN), Natal, RN, Brazil.

${ }^{4}$ Schizophrenia Program, Interdisciplinary Laboratory of Clinical Neurosciences, Department of Psychiatry, Universidade Federal de São

Paulo (UNIFESP), São Paulo, SP, Brazil. ${ }^{5}$ Schizophrenia Research Program and Department and Institute of Psychiatry, School of Medicine, USP, São Paulo, SP, Brazil.

Depot antipsychotic drugs, or long-acting injectable antipsychotics (LAls), have been available since the 1960s and were conceived mainly to improve adherence to treatment in patients with schizophrenia. Even though it is known that more than half of the patients with schizophrenia do not properly comply with oral medication treatments ${ }^{1}$ and that LAls are the best choice for such cases, the prescription of these drugs has significantly decreased over the years. Indeed, less than $30 \%$ of patients with schizophrenia are currently treated with LAls. ${ }^{2}$

There is a widespread belief that LAls have more and even worse adverse effects than their equivalent oral preparations. Although there is support for this notion in the literature, ${ }^{3}$ a recent review of randomized controlled studies has shown that, whereas some of the LAls currently available may cause similar or more severe side effects, others such as risperidone have similar or even milder side-effect profiles than their oral counterparts. ${ }^{4}$

In addition, because LAls have been used over the past 50 years, many psychiatrists consider that they are "old-fashioned" drugs. Notwithstanding, the fact is that second-generation LAls such as risperidone became available in 2002, and paliperidone palmitate was only recently released in the market, in $2009 .^{5}$

Recent evidence has shown that LAls are more effective in preventing both relapse and re-hospitalization when compared with oral medications. ${ }^{2}$ Furthermore, the availability of depot medication gives psychiatrists the opportunity to readily identify non-adherence to treatment and to reduce the risk of self-intoxication by inappropriate medication use. ${ }^{2}$

A large body of clinical and neurobiological evidence has shown that psychotic relapse is associated with brain volume reductions and clinical deterioration. This effect is particularly important in the years following the first psychotic episode. Psychiatrists usually consider LAls

Correspondence: Jaime EC Hallak, Hospital das Clínicas da FMRPUSP, Av. Bandeirantes, 3900, $3^{\circ}$ andar, CEP 14048-900, Monte Alegre, Ribeirão Preto, SP, Brazil.

E-mail: jhallak@fmrp.usp.br as their last choice, after the occurrence of several psychotic episodes, with their deleterious effects. Indeed, LAls are not commonly indicated for first-episode psychosis, despite the high rates of non-adherence to treatment observed in this group of patients. Nevertheless, advantages of the use of LAls have been consistently reported, and studies have shown that the risk of re-hospitalization for patients receiving depot medications is about one-third of that for patients receiving oral medications. ${ }^{6}$

Several studies have shown that the prevention of psychotic relapse has major implications for the minimization of damage and of some disabilities that typically affect these individuals. ${ }^{7}$ In other words, the earlier the pharmacological treatment is implemented, the better the prognosis. In this context, the use of depot antipsychotics could provide psychiatrists with the assurance that this window of opportunity would not be missed, especially in the initial phase of the disease - up to 5 years after the onset of psychotic symptoms -, a critical period for prognosis.

We expect that the attitudes of mental health professionals towards the use of LAls become more based on facts than on myths. In this way, perhaps, misconceptions regarding depot antipsychotic drugs could be mitigated. Why aren't we prescribing LAls more often? This is the question we all should ask ourselves.

\section{Disclosure}

João Paulo Maia-de-Oliveira and João Paulo Machadode-Sousa have received grants from Conselho Nacional de Desenvolvimento Científico e Tecnológico (CNPq). Rodrigo A. Bressan has received grants from Janssen, Eli-Lilly, Lundbeck, Novartis, and Roche; has served as a consultant or advisory board member for Astra Zeneca, Janssen, and Lundbeck; and is a shareholder at Biomolecular Technology Ltda. Helio Elkis has received grants from Fundação de Amparo à Pesquisa do Estado de São Paulo (FAPESP), Janssen, Novartis, and Roche; has received speaker's honoraria from Janssen, Moksha 8, Novartis, and Roche; has served as a consultant or 
advisory board member for Janssen, Pfizer, Lundbeck, Roche; and has received other honoraria from Janssen, Lilly, and Novartis. Jaime E. C. Hallak has received grants from Conselho Nacional de Desenvolvimento Científico e Tecnológico (CNPq); and has received honoraria and travel support from Astra Zeneca, Janssen, and Novartis.

\section{References}

1 Rosa MA, Marcolin MA, Elkis H. Evaluation of the factors interfering with drug treatment compliance among Brazilian patients with schizophrenia. Rev Bras Psiquiatr. 2005;27:178-84.

2 Leucht C, Heres S, Kane JM, Kissling W, Davis JM, Leucht S. Oral versus depot antipsychotic drugs for schizophrenia--a critical systematic review and meta-analysis of randomised long-term trials. Schizophr Res. 2011;127:83-92.

3 Taylor D. Psychopharmacology and adverse effects of antipsychotic long-acting injections: a review. Br J Psychiatry Suppl. 2009;52:S139.

4 Zhornitsky S, Stip E. Oral versus long-acting injectable antipsychotics in the treatment of schizophrenia and special populations at risk for treatment nonadherence: a systematic review. Schizophr Res Treatment. 2012;2012:407171.

5 Fleischhacker WW. Second-generation antipsychotic long-acting injections: systematic review. Br J Psychiatry Suppl. 2009;52:S2936.

6 Tiihonen J, Haukka J, Taylor M, Haddad PM, Patel MX, Korhonen P. A nationwide cohort study of oral and depot antipsychotics after first hospitalization for schizophrenia. Am J Psychiatry. 2011;168:603-9.

7 Buckley PF, Correll CU, Miller AL. First-episode psychosis: a window of opportunity for best practices. CNS Spectr. 2007;12:1-12; discussion 3-4; quiz 5-6. 